\title{
Optimization of Application of Delactosed Whey Permeate Treatment to Extend the Shelf-Life of Fresh Cut Tomato Using Response Surface Methodology.
}

\author{
Lubna Ahmed \\ Technological University Dublin, lubna.ahmed@tudublin.ie \\ Ana Belen Martin-Diana \\ Technological University Dublin, anabelen.martindiana@tudublin.ie \\ Daniel Rico \\ Technological University Dublin, daniel.rico@tudublin.ie
}

See next page for additional authors

Follow this and additional works at: https://arrow.tudublin.ie/schfsehart

Part of the Microbiology Commons

\section{Recommended Citation \\ Ahmed, L., Martin-Diana, A.B., Rico, D., and Barry-Ryan, C. (2011) Optimization of Application of Delactosed Whey Permeate Treatment To Extend the Shelf Life of Fresh-Cut Tomato Using Response Surface Methodology. Journal of Agriculture \& Food Chemistry, 59, 2377-2385 doi: 10.1021/jf103809f}

This Article is brought to you for free and open access by the School of Food Science and Environmental Health at ARROW@TU Dublin. It has been accepted for inclusion in Articles by an authorized administrator of ARROW@TU Dublin. For more information, please contact arrow.admin@tudublin.ie, aisling.coyne@tudublin.ie, gerard.connolly@tudublin.ie.

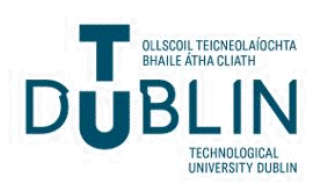




\section{Authors}

Lubna Ahmed, Ana Belen Martin-Diana, Daniel Rico, and Catherine Barry-Ryan 
Full Title

2

Optimization of Application of Delactosed Whey Permeate Treatment to Extend the Shelf-life of Fresh-cut Tomato using Response Surface Methodology

Names(s) Authors(s)

Lubna Ahmed $^{\mathrm{a} *}$, Daniel Rico ${ }^{\mathrm{b}}$, Ana B. Martin-Diana ${ }^{\mathrm{c}}$ and Catherine Barry-Ryan ${ }^{\mathrm{a}}$

\section{Author Affiliation(s)}

$13{ }^{\text {a }}$ School of Food Science and Environmental Health, Dublin Institute of Technology 14 (DIT), Cathal Brugha Street, Dublin 1, Ireland.

$15{ }^{\mathrm{b}}$ Food Technology Department, Public University Nevarra, Pamplona, Spain.

$16{ }^{\mathrm{c}}$ Agricultural Technological Institute of Castilla and Leon. Government of Castilla and 17 Leon, Finca Zamadueñas, Valladolid, Spain.

21 *Corresponding Author: Lubna Ahmed, School of Food Science and Environmental

22 Health, Dublin Institute of Technology (DIT), Cathal Brugha Street, Dublin 1, Ireland.

23 Phone: 35314024442, Fax: +35314024495, e-mail: $\underline{\text { lahmed@ dit.ie }}$ 


\section{ABSTRACT}

25 Optimization of delactosed whey permeate (DWP) treatment for fresh-cut tomato was

26 accomplished by evaluating different quality, nutritional and microbial markers. Response

27 surface methodology was applied to obtain polynomial model equations. DWP

28 concentration $(0-5 \%)$ and storage ( 0 - 10 days) were used as independent factors in order

29 to optimize the process. The analyses showed that increases in DWP concentration

30 extended the quality of the fresh-cut tomato significantly $(\mathrm{p}<0.05)$ by maintaining texture,

31 antioxidant activity (FRAP) and controlling the spoilage during the storage. However,

32 concentrations $>3 \%$ were scored unacceptable by the sensory panel due to perceived off-

33 odours. DWP treatment also improved retention of ascorbic acid and lycopene over storage.

34 The total aerobic counts and yeast and moulds were reduced by $\sim 1.5 \log \mathrm{cfu} / \mathrm{g}$ and $\sim 1.0 \log$

$35 \mathrm{cfu} / \mathrm{g}$ respectively after 10 days of storage treated with $3 \%$ DWP. Predicted models were

36 highly significant $(\mathrm{p}<0.05)$ for all the markers studied in fresh-cut tomato with high

37 regression coefficients $\left(\mathrm{R}^{2}\right)$ ranging from 0.79 to 0.99 . The study recommends the use of

38 DWP at a concentration of $3 \%$ to extend the shelf-life of fresh-cut tomato by preserving its

39 quality and antioxidant properties during storage.

40

41 KEY WORDS: Whey permeate; Fresh-cut; Tomato; Preservation; RSM. 


\section{INTRODUCTION}

44 Whey permeate is a by-product generated in the production of whey protein concentrate

45 from cheese whey. The main ingredients of whey permeate are water, lactose, peptides and

46 minerals. Whey and whey ultra-filtrated permeate have been proposed for use as a natural

47 antioxidant in foods (1). Whey protein and peptides are widely used as bioactive and

48 nutritional ingredients in health and food products. Lactoferrin, $\alpha$-lactalbumin and $\beta$ -

49 lactoglobulin are proteins with antimicrobial properties. Casein macropeptide (CMP), $\alpha_{1^{-}}$

50 and $\alpha_{2}$ - caseins are further examples of whey antimicrobial peptides (2). Whey peptides

51 exhibit a growing number of biological effects including anti-hypertensive, anti-cancer,

52 hypocholesterolemic, opiodergic, and anti-microbial activities (3). Whey is used as a

53 fermentation feedstock for the production of lactic acid, acetic acid, propionic acid, ethanol,

54 and single cell protein, etc. (4). However, these applications still do not utilize all the whey

55 produced and new uses for this by-product are needed. Their application into other products

56 would help the cheese industry to partially solve the problem of whey disposal.

57 Continued growth in ready-to-eat vegetable industry has been largely driven by increasing

58 demand for convenient, fresh and healthy foods. Increasing the quality retention and shelf-

59 life of these products during storage is an important demand of the industry and consumers

60 (6). The marketing of fresh-cut vegetables is limited by their short shelf-life due to quick

61 decline in post-processing quality. Chlorinated water (50-200 ppm) is widely used to wash

62 fruits and vegetables as well as fresh-cut produce in order to preserve their quality.

63 However, the possible formation of carcinogenic chlorinated compounds in water

64 (chloramines and trihalomethanes) has called into question the use of chlorine for this

65 purpose (7). Therefore the use of a novel alternative with a low-cost and as effective as

66 chlorine is desired by industry. In recent years interest is growing in the use of natural 
67 products for the preservation of fresh-cut produce. Research and commercial applications

68 have shown that natural components could replace traditional washing agents (8). The

69 development of chlorine-free fruit and vegetable products enriched with natural bio-

70 products could contribute greatly to a new and growing market, where the consumers'

71 concerns about their health are met.

72 Tomato is one of the most widely used and versatile vegetable crops. It is consumed fresh

73 and also used to manufacture a wide range of processed products. The consumption of

74 tomatoes is currently considered as an indicator of good dietary habit and healthy life style.

75 This fruit has undoubtedly assumed the status of a food with functional properties,

76 considering the overwhelming epidemiological evidence for its capacity to reduce the risk

77 of chronic diseases such as cardiovascular disease and cancer (9). This protective function

78 is attributed to antioxidant compounds like lycopene and other carotenoids (pro-vitamin A,

79 beta-carotene), ascorbic acid, vitamin $\mathrm{E}$ and flavonoids (10).

80 Response surface methodology (RSM) is a statistical technique which allows the user to

81 identify optimal conditions for a selected response while minimizing the number of

82 experiments required. When many factors and interactions affect desired response, RSM is

83 an effective tool for optimizing the process. Central composite design (CCD) is the most

84 popular form of RSM as it has been utilized by a number of researchers to optimize various

85 food processing methods such as, steamer jet-injection, milling, extraction, fermentation,

86 etc. $(11,12)$. In the present study, RSM was used to model the effect of DWP concentration

87 and storage time on fresh-cut tomato. The aim of this paper is to optimize the use of DWP

88 to extend the shelf-life of fresh-cut tomato with optimum quality, nutritional and microbial

89 properties for the industry.

90 MATERIALS AND METHODS 


\section{$91 \quad$ Sampling}

92 Irish vine ripened tomatoes (Lycopersicon esculentum L. Mill.) cv. Moneymaker were

93 purchased from a local supermarket (Dunnes Stores). According to the grower, the tomato

94 plants were grown commercially in a greenhouse with a $14 \mathrm{~h}$ light period from February

95 until November. The aerial environment of the greenhouse and crop irrigation and nutrition

96 were precisely controlled. The temperature of the greenhouse was $16-21{ }^{\circ} \mathrm{C}$ which is

97 optimum for lycopene synthesis in tomato fruits. The tomatoes were then brought to the

98 food processing lab and stored at $4{ }^{\circ} \mathrm{C}$ before processing.

\section{Preparation of treatment solution}

100 Delactosed whey permeate (liquid) were kindly supplied by Glanbia Ltd. Ingredients,

101 Ireland. Delactosed whey permeate (DWP) was obtained after removal of lactose crystals

102 from whey permeate. The total solid, proteins, moisture content and pH of DWP solution

103 were $32.9 \%, 0.16 \%, 72 \%$ and 5.0 respectively. DWP liquid was diluted to different

104 concentrations $(0-5 \%)$ with distilled water.

\section{Processing}

106 Whole tomatoes were rinsed briefly in water prior to washing in order to avoid soil

107 contamination. Washing treatment was performed by double treatment of DWP treatment

108 solution $(0-5 \%)$. First the tomatoes were immersed in DWP solution (200 g tomatoes/L)

109 for $1 \mathrm{~min}$ (with agitation). The tomatoes were sliced $6 \mathrm{~mm}$ in thickness with a commercial

110 slicing machine (Maxwell chase MCT-25, Baltimore Innovations, UK). Secondly the DWP 111 treatment solution $(0-5 \%)$ were sprayed over the sliced tomato. The tomatoes were then

112 air-dried for 30 mins in RT. Processed tomatoes were then pooled, mixed and $\sim 100$ grams

113 placed in a polypropylene tray (180 mm length $\times 130 \mathrm{~mm}$ width $\times 25 \mathrm{~mm}$ depth) from Sharp

114 Interpack Ltd., UK containing one layer of absorbent paper on the bottom (Fresh-R-Pax 
115 absorbent pads, Maxwell Chase Technologies, Atlanta). The principal ingredient in fresh-R-

116 Pax absorbent pads is food grade sodium carboxymethyl cellulose (CMC), a common

117 ingredient in ice-cream, sauces, low-fat foods, etc. The trays were then packed in bags

$118(200 \times 320 \mathrm{~mm})$ of $35 \mu \mathrm{m}$ oriented polypropylene film (OPP) with permeability at $23{ }^{\circ} \mathrm{C}$ and

$11990 \% \mathrm{RH}$ of $3.3 \times 10^{-12} \mathrm{~mol} / \mathrm{s} / \mathrm{m}^{2} / \mathrm{Pa}$ for $\mathrm{O}_{2}$ and $3.1 \times 10^{-9} \mathrm{~mol} / \mathrm{s} / \mathrm{m}^{2} / \mathrm{Pa}$ for $\mathrm{CO}_{2}($ Amcor

120 Flexibles Europe-Brighouse, United Kingdom). The packages were then heat-sealed under

121 atmospheric conditions and stored at $4{ }^{\circ} \mathrm{C}$ for 10 days (6).

\section{Experimental design}

123 RSM was used in this work to study the effects of two independent variables [DWP

124 concentration ( $0-5 \%)$ and storage time (0 - 10 days)] on different quality, nutritional and

125 microbial markers (dependent variables) on fresh-cut tomato using the Design Expert

126 Version 7.1.3 software (Stat-Ease, Inc., Minneapolis, MN). The experimental design was

127 based on a central composite design (CCD). The data obtained from the CCD design was

128 fitted with a second order polynomial equation. The equation was as follows:

$129 Y=\beta_{0}+\sum_{i=1}^{2} \beta_{i} X_{i}+\sum_{i=1}^{2} \beta_{i i} X_{i}^{2}+\sum_{i} \sum_{j=i+1} \beta_{i j} X_{i} X_{j}$

130 where $Y$ is the predicted response; $\beta_{0}$ is a constant; $\beta_{i}$ is the linear coefficient; $\beta_{i i}$ is the

131 quadratic coefficient, $\beta_{i j}$ is the interaction coefficient; and $X i$ and $X j$ are independent

132 variables. The adequacy of the model was determined by evaluating the lack of fit,

133 coefficient of regression $\left(\mathrm{R}^{2}\right)$ and the Fisher test value (F-value) obtained from the analysis

134 of variance (ANOVA). Statistical significance of the model and model variables was

135 determined at the $5 \%$ probability level $(\mathrm{p}<0.05)$. The software uses the quadratic model

136 equation (1) to build response surfaces. The complete design consisted of 11 experimental

137 points including three replications of the central point. The actual values of the factors for

138 the experimental designs are given in Table 1. 


\section{Markers analysis of fresh-cut tomato}

140 Different quality (headspace gas composition, dry matter, $\mathrm{pH}$, texture, color changes and

141 sensory analysis), nutritional (ascorbic acid, lycopene, total phenols, antioxidant activity as

142 measured by FRAP) and microbial (total aerobic bacteria and yeast and moulds) markers

143 were monitored throughout the 10 days of storage of fresh-cut tomato stored at $4{ }^{\circ} \mathrm{C}$.

\section{Quality markers}

\section{Headspace gas composition}

146 Changes in $\mathrm{O}_{2}$ and $\mathrm{CO}_{2}$ concentration of the headspaces of the fresh-cut tomatoes packages

147 were monitored during the shelf-life of fresh-cut tomatoes. A Gaspace analyzer (Systech

148 Instruments, $\mathrm{UK}$ ) was used to monitor $\mathrm{O}_{2}$ and $\mathrm{CO}_{2}$ levels. Gas extractions were performed

149 with a hypodermic needle, inserted through an adhesive septum previously fixed to the

150 bags, at a flow rate of $150 \mathrm{ml} / \mathrm{min}$ for $10 \mathrm{sec}$. Three bags per treatment were monitored for

151 each experiment and all bags for other analyses were checked before analysis (5).

\section{$152 \mathbf{p H}$}

153 Ten-gram of tomato tissue was blended for 2 min. Then the $\mathrm{pH}$ was measured at room

154 temperature using an Orion research $\mathrm{pH}$-meter, UK.

\section{Moisture Content}

156 Moisture content was determined by AOAC method (1990) (Method 925.098). The tomato

157 samples were dried at $105^{\circ} \mathrm{C}$ overnight.

\section{Texture}

159 Four measurements were made on each slice, two in the outer pericarp and two in the radial

160 pericarp, applying the force in the axial direction. The force necessary to cause a

161 deformation of $3 \mathrm{~mm}$ with a speed of $0.02 \mathrm{~mm} / \mathrm{s}$ was recorded using a an Instron texture

162 analyzer (Instron 4302 Universal Testing Machine, Canton MA, USA), with a $3.5 \mathrm{~mm}$ 
163 diameter flat faced cylindrical probe. Only the central slice in the stack was used in the

164 analyses. The firmness measurement was performed immediately after removing the slice

165 from the storage chamber (at storage temperature). Data were analyzed with the Instron

166 series IX software for Windows.

167 Color

168 For color analysis each piece of tomato in the storage pack was analyzed individually to

169 minimize the variability of the product. Color was quantified using a Color Quest XE

170 colorimeter (HunterLab, Northants, UK). A tomato slice was placed directly on the

171 colorimeter sensor (3.5 cm of diameter) and measured. 20 - 30 measurements were taken

172 per treatment and day. The $\mathrm{L}^{*}$ parameter (lightness index scale) range from 0 (black) to 100

173 (white). The $\mathrm{a}^{*}$ parameter measures the degree of red $\left(+\mathrm{a}^{*}\right)$ or green $\left(-\mathrm{a}^{*}\right)$ color and the $\mathrm{b}^{*}$

174 parameter measures the degree of yellow $\left(+b^{*}\right)$ or blue $\left(-b^{*}\right)$ color. The CIE $L^{*} a^{*} b^{*}$

175 parameters were converted to Hue $\left(\arctan b^{*} / a^{*}\right)$ and Chroma $\left(a^{* 2}+b^{* 2}\right)^{1 / 2}$.

\section{Sensory analysis}

177 Analytical descriptive tests were used to discriminate between the sensory quality attributes

178 of fresh-cut tomato. A panel of 12 judges aged 20 - 35 years (eight females and four males,

179 all members of the School of Food Science and Environmental Health, DIT) was trained in

180 discriminate evaluation of fresh-cut tomato. Panelists were required to score changes in

181 fresh appearance, texture, color, aroma and general acceptability. Before starting of sensory

182 experiments, panelists were familiarized with the product and scoring methods. This

183 consisted of demonstration exercises involving examination of fresh-cut tomatoes at

184 different levels of deterioration and agreeing appropriate scores. After becoming familiar

185 with the test facilities and scoring regime, they were invited to score samples. This

186 procedure was repeated several times until a level of consistency in scoring was obtained. 
187 The same packages were scored during the entire trial for sensory analysis (10 days).

188 During this training, the samples were presented to the panel to evaluate and measure the

189 reproducibility of the judges' answer and their capability in discriminating among samples.

190 During the analyses, samples were presented in randomized order to minimize possible

191 sequence influence.

192 Three DWP concentration (1, 3 and $5 \%$ ) and a control (chlorine $120 \mathrm{ppm})$ treated fresh-cut

193 tomatoes were evaluated by the sensory panel by the sensory panel at regular intervals

194 during storage (1, 4, 7 and 10). Fresh appearance, color, texture, aroma and general

195 acceptability of samples were scored on a hedonic scale of 1 to 9 , where a score of one

196 indicated a product of very poor quality, etc. (13). The evaluation was carried out in the

197 sensory evaluation laboratory. Products were placed in plastic cups with lid, on a white

198 surface and judges were isolated from each-other in a booth in an odor-free environment.

199 The results of the sensory analysis were reported as means of three separate trials. Data

200 were analyzed using Compusense ${ }^{\circledR}$ Five software (Release 4.4, Ontario, Canada).

$201 \quad$ Nutritional markers

202 Ascorbic acid

203 The ascorbic acid content in fresh-cut tomatoes was analyzed by HPLC with a slight

204 modification of the method described by Lee and Castle (14). A tomato sample (2.5 g) was

205 weighed and $25 \mathrm{ml}$ of $6 \%$ meta-phosphoric acid (pH 3.0) was added to it. The sample was

206 homogenized for $1 \mathrm{~min}$ at 24,000 rpm using an Ultra-Turrax T-25 Tissue homogenizer.

207 Then the sample was shaken with a Gyrotory Shaker G-2 (USA) for $2 \mathrm{hrs}$ at $150 \mathrm{rpm}$ and

208 centrifuged for $15 \mathrm{~min}$ at $785 \times \mathrm{g}$ at $4^{\circ} \mathrm{C}$ ) (Sanio MSE Mistral 3000ii, UK). Following

209 centrifugation, $10 \mathrm{ml}$ of the supernatant was filtered through PTFE syringe filters (pore size 
$2100.45 \mu \mathrm{m}$, Phenomenex, UK) and stored at $-20^{\circ} \mathrm{C}$ in foil covered plastic test tubes for

211 further analysis by HPLC.

212 The analysis of ascorbic acid content was performed with Waters 600 Satellite HPLC, with

213 a reverse phase analytical polymeric $\mathrm{C}_{18}$ column $(150 \times 4.6 \mathrm{~mm}, 5 \mu \mathrm{m})$ (Waters, Ireland)

214 with a UV-tunable absorbance detector (Waters 486) at $245 \mathrm{~nm}$. Ten $\mu 1$ of the sample was

215 injected. An isocratic mobile phase of $25 \mathrm{mM}$ monobasic potassium phosphate (pH 3.0)

216 with a flow rate of $1.0 \mathrm{ml} / \mathrm{min}$ was used. Five concentrations of ascorbic acid standard in 6

$217 \%$ meta-phosphoric acid in the range $10-50 \mu \mathrm{g} / \mathrm{ml}$ were injected.

\section{Lycopene}

219 Ten grams of tomato samples were weighed and transferred into a $100 \mathrm{~mL}$ beaker (wrapped 220 with aluminum foil). A 50-ml volume of hexane-acetone-ethanol solution $(2: 1: 1 \mathrm{v} / \mathrm{v} / \mathrm{v})$

221 containing $2.5 \%$ BHT was added to solubilize the lycopene (15). Following this the

222 samples were homogenized with an Ultra-Turrax T-25 tissue homogenizer for 1 min at

223 20,500 rpm. The samples were then shaken with a Gyrotory Shaker G-2 (USA) for 2 hrs at

$224150 \mathrm{rpm}$ followed by $10 \mathrm{ml}$ of distilled water was added and stirred for additional $10 \mathrm{~min}$.

225 The polar and non-polar layers were separated, and the upper hexane layer was collected 226 and filtered through a $0.45 \mu \mathrm{m}$ PVDF membrane filter. It was transferred to a new $15 \mathrm{ml}$ 227 aluminum wrapped test tubes and kept at $-80{ }^{\circ} \mathrm{C}$ for analysis.

228 The analysis of lycopene was performed with Waters 600 Satellite HPLC, with a reverse

229 phase analytical polymeric $\mathrm{C}_{18}$ column $(150 \times 4.6 \mathrm{~mm}, 5 \mu \mathrm{m})$ (Waters, Ireland) with a UV

230 tunable absorbance detector (Waters 486) for spectrometric peak. The lycopene peaks were 231 identified at $475 \mathrm{~nm}$. An isocratic mobile phase of methyl t-butyl ether/methanol/ethyl 232 acetate (40:50:10, v/v) with a flow rate of $1 \mathrm{ml} / \mathrm{min}$ was used. The column temperature and 233 mobile phase was maintained at $25^{\circ} \mathrm{C}$. Analyses were performed under dim light to prevent 
234 sample degradation by photo-oxidation. Three concentrations of lycopene standard in the

235 range $0.01-0.03 \mathrm{mg} / \mathrm{ml}$ were injected.

236 Total phenols

237 For extraction, $1.25 \mathrm{~g}$ of tomato sample was weighed and $25 \mathrm{ml}$ of methanol was added.

238 Following this the sample was homogenized in a $50 \mathrm{ml}$ tube with an Ultra-Turrax T-25

239 tissue homogenizer for $1 \mathrm{~min}$ at 24,000 rpm. The samples were then thoroughly mixed with

240 a vortex mixer (V400 Multitude Vortexer, Alpha laboratories) for $2 \mathrm{hrs}$ at $150 \mathrm{rpm}$. Then it

241 was centrifuged for 15 min at $785 \times g$ using a Sanyo MSE Mistral 3000i, UK. Following

242 centrifugation, $10 \mathrm{ml}$ samples of the supernatant were filtered through PTFE syringe filters

243 (pore size $0.45 \mu \mathrm{m}$, Phenomenex, UK). Finally the extracts were stored at $-20{ }^{\circ} \mathrm{C}$ in foil

244 covered plastic test tubes for further analysis.

245 Total phenol content of tomatoes was determined using the Folin-Ciocalteu method (16). In

246 a $1.5 \mathrm{ml}$ Eppendorf tube, $100 \mu \mathrm{l}$ of appropriately diluted methanolic extract, $100 \mu \mathrm{l}$ of

$247 \mathrm{MeOH}$ and $100 \mu \mathrm{l}$ of FC reagent were added and vortexed. After exactly $1 \mathrm{~min}, 700 \mu \mathrm{l}$ of

248 sodium carbonate (20\%) was added, and the mixture was vortexed and allowed to stand at

249 room temperature in the dark for $20 \mathrm{~min}$. Then the tubes were centrifuged at $14,737 \times \mathrm{g}$ for

$2503 \mathrm{~min}$. The absorbance of the supernatant was read at $735 \mathrm{~nm}$ in $1 \mathrm{ml}$ plastic cuvettes.

251 Methanol was used in substitution of sample, undergoing the same procedure, for the blank

$252\left(\mathrm{MeOH}+\mathrm{FCR}+\mathrm{Na}_{2} \mathrm{CO} 3\right)$. Each sample of the three batches was measured in triplicate.

253 Results were expressed as mg/L gallic acid equivalents (GAE).

254 Antioxidant activity test - ferric ion reducing antioxidant power assay (FRAP)

255 The FRAP assay was carried out as described by Stratil et al. (17) with a slight

256 modification. Extraction was done same way as total phenol. 
257 The FRAP reagent was prepared by mixing $38 \mathrm{mM}$ sodium acetate (anhydrous) in distilled

258 water $\mathrm{pH} 3.6,20 \mathrm{mM} \mathrm{FeCl} 3.6 \mathrm{H}_{2} \mathrm{O}$ in distilled water and $10 \mathrm{mM}$ 2,4,6-tri(2-pyridyl)-s-

259 triazine (TPTZ) in $40 \mathrm{mM} \mathrm{HCl}$ in proportions of 10:1:1. This reagent was freshly prepared

260 before each experiment. In a $1.5 \mathrm{ml}$ Eppendorf tube $100 \mu \mathrm{l}$ of appropriately diluted

261 methanolic extract and $900 \mu \mathrm{l}$ FRAP Reagent were added and vortexed. After that they

262 were kept for $40 \mathrm{~min}$ in the heating blocks at $37^{\circ} \mathrm{C}$, covered with tin foil. The absorbance

263 of the supernatant was read at $593 \mathrm{~nm}$ in $1 \mathrm{ml}$ plastic cuvettes. Each sample of the three

264 batches was measured in triplicate.

\section{Microbiological markers}

266 Microbiology analyses were carried out on the samples before and after the treatment at

267 regular intervals through the storage period. $25 \mathrm{~g}$ of tomatoes were blended in $225 \mathrm{ml}$ of

268 peptone saline with a Stomacher circulator homogenizer. Enumeration and differentiation

269 of total aerobic counts were quantified at $30^{\circ} \mathrm{C}$ in plate count agar (PCA) over $72 \mathrm{hrs}$. Yeast

270 and moulds were quantified at $25^{\circ} \mathrm{C}$ in potato dextrose agar (PDA) over $72 \mathrm{hrs}$. The results

271 were expressed as $\log _{10}$ colony forming units per gram $(\mathrm{CFU} / \mathrm{g})$.

272 Validation of the model

273 The predictive performance of the developed models describing the combined effect DWP

274 concentration $\left(\mathrm{X}_{1}\right)$ and storage time $\left(\mathrm{X}_{2}\right)$ on independent variables (quality, nutritional and

275 microbiological markers) of fresh-cut tomato were validated in a separate set of selected

276 conditions. The criterion used to characterize the fitting efficiency of the data to the model

277 was the multiple correlation coefficients $\left(\mathrm{R}^{2}\right)$ and their average mean deviation (E, Eq. 2).

278

$$
E(\%)=\frac{1}{n_{e}} \sum_{i=1}^{n}\left\|\frac{V_{E}-V_{P}}{V_{E}}\right\| \times 100
$$


279 where, $n_{e}$ is the number of experimental data, $V_{E}$ is the experimental value and $V_{P}$ is the

280 predicted value.

\section{Statistical analysis}

282 RSM was used to fit the experimental data to the quadratic polynomial equation to obtain

283 coefficients of the equations. The model and statistical analyses and contour plots were

284 analyzed using Design Expert, version 7.1.3 software (Stat-Ease, Inc., Minneapolis, MN).

285 For comparison of DWP at optimum concentration with fresh-cut tomato in sensory

286 analysis trials ANOVA (Multifactor and one-way) was performed to examine differences

287 between treatment, storage time and interaction of both factors with each one of the

288 variables studied. Means were compared by significant difference (LSD) test, at a

289 significance level $(\mathrm{p}<0.05)$ using the Design Expert software.

290 RESULTS AND DISCUSSION

291 Quality markers

\section{Headspace gas composition}

293 Eqs. (2 and 3) described the models obtained for $\mathrm{O}_{2}$ and $\mathrm{CO}_{2}$ headspace composition. The

294 models explained $99.33 \%$ of variation of oxygen and $99.16 \%$ of carbon dioxide due to the

295 treatment effect of different concentrations $(0-5) \%$ of delactosed whey permeate and

296 storage time (0 - 10 days). Significant linear effects $(\mathrm{p}<0.05)$ of storage were observed for

297 oxygen. In case of carbon dioxide gas significant linear and quadratic effects $(\mathrm{p}<0.05)$ of

298 storage were observed. DWP concentration did not affect significantly $(\mathrm{p}>0.05)$ the $\mathrm{O}_{2}$ and

$299 \mathrm{CO}_{2}$ levels. The oxygen gas decreased and the carbon dioxide gas increased throughout

300 storage, as expected. Oxygen decreased from atmospheric concentration (21\% - packaging

301 conditions) to values around $14 \%$ (Figure 1A) and carbon dioxide levels reached from 1 to

$3027 \%$ at the end of the storage (Figure 1B). 
$304 Y_{\text {Carbon dioxide }}=1.17682+0.29126 X_{2}+0.030102 X_{2}^{2} ; R^{2}=99.16 \%$

\section{$305 \mathbf{p H}$}

306 The $\mathrm{pH}$ was significantly $(\mathrm{p}<0.05)$ affected by DWP concentration and storage time. The

307 polynomial model (Eq. 4) explained $84.17 \%$ of pH data variation with these two factors. A

308 significant $(\mathrm{p}<0.05)$ linear effect of DWP concentration and storage were observed (Figure

309 1C). A general increase of $\mathrm{pH}$ was observed over storage, which could be due to an increase

310 in the bacterial growth (18). Similar results were found by Roura et al. (19), which

311 attributed the gradual increases in the $\mathrm{pH}$ values of spinach leaves and Swiss chard to the

312 microbial growth. DWP concentration had significantly $(\mathrm{p}<0.05)$ negative linear effect on

$313 \mathrm{pH}$. Higher inhibition of bacterial growth with increased DWP concentrations could have

314 slowed down the increase of $\mathrm{pH}$ over storage.

$315 Y_{p H}=4.52955-0.17759 X_{1}+0.10786 X_{2} ; R^{2}=84.17 \%$

\section{Texture}

317 The model (Eq. 5) explained $86.24 \%$ of tomato texture variation. A significant $(\mathrm{p}<0.05)$

318 decrease in texture was observed during storage (Figure 1D). DWP concentration affected

319 significantly $(\mathrm{p}<0.05)$ tomato firmness measurement.

$320 Y_{\text {Texture }}=7.13840+0.39508 X_{1}-0.53984 X_{2} ; R^{2}=86.24 \%$

321 The presence of calcium in the whey permeates may have contributed to maintain the

322 firmness of tomato during storage (20). Calcium has positive effects of on the firmness of

323 fresh-cut fruits. Different calcium salts have been used for firmness improvement of fresh

324 fruits and vegetables. Calcium carbonate and calcium citrate are the main calcium salts

325 added to foods in order to enhance the nutritional value. Calcium chloride has been widely 
326 used as preservative and firming agent in the fruit and vegetable industry for whole and

327 fresh-cut commodities (21).

328 Color

329 The variations in color parameters (luminosity, $\mathrm{a}^{*}, \mathrm{~b}^{*}$, Hue and Chroma) due to DWP

330 concentration and storage time are shown in Table 2. The polymeric model explained 79.20

$331 \%$ of the variability of the luminosity due to the effect of concentration and storage time.

332 Fresh-cut tomatoes showed significant decrease in luminosity during storage $(\mathrm{p}<0.05)$. This

333 was in agreement with the findings of Lana et al. (22). The decrease in luminosity during

334 the storage in fresh-cut tomato is attributed to the pigment break down, mainly carotenoids

335 (15). There were no differences in L* values between DWP treatment concentrations.

336 A significant increase of $\mathrm{a}^{*}$ was observed with increasing DWP concentrations. The model

337 explained $87.59 \%$ of the variability of $a^{*}$ due to the effect of DWP concentration and

338 storage time. The parameter $\mathrm{a}^{*}$ increased significantly $(\mathrm{p}<0.05)$ during storage. The $\mathrm{a}^{*}$

339 value is an important parameter for red color development and the degree of ripening in

340 tomato. Lana et al. (22) also showed increasing a* values of tomatoes during storage.

341 The $b^{*}$ values were analyzed through storage time in fresh-cut tomato enriched with

342 different concentrations of DWP. The model explained $90.66 \%$ of the changes of the $\mathrm{b}^{*}$

343 value during storage. The parameter $b^{*}$ was not affected by DWP treatment concentrations.

344 The decreasing trend of $b^{*}$ values throughout the storage showed that the fresh-cut

345 tomatoes did not have any chilling injury stored at $4{ }^{\circ} \mathrm{C}$ as it is the optimum storage

346 temperature of fresh-cut fruits and vegetables (23).

347 Changes in Hue and Chroma were explained by $95.21 \%$ and $85.32 \%$ respectively by the

348 model. The Hue and Chroma values were affected by the storage time. Hue has a negative

349 correlation with the maturity of the tomato. As the tomatoes mature during storage, Hue 
350 decreases. The concentration of DWP used did not induce significant $(p>0.05)$ changes in

351 Hue and Chroma values.

352 Sensory analysis

353 All the attributes, fresh appearance, texture, aroma and general acceptability, except color

354 decreased significantly $(\mathrm{p}<0.05)$ during storage which is associated with a loss of quality

355 (Figure 2). However, the values at the end of the storage (10 days) were still above the

356 acceptability threshold of 5 for all the attributes scored. The non-hypoxic oxygen and

357 carbon-dioxide concentration in the packages might have helped to maintain acceptable

358 levels of color and aroma (24). Color increased during storage. The higher values for the

359 color parameter at the later stage of storage could be explained by the ripening of the fresh-

360 cut tomatoes during storage. Sensory scores of color was supported by the increased a*

361 value recorded by the colorimeter during storage of fresh-cut tomatoes. The treatments

362 affected significantly the sensory parameters of the samples. A significant $(\mathrm{p}<0.05)$

363 reduction in aroma and general acceptability in samples treated with more than $3 \%$ of

364 DWP concentrations was observed. The panelists considered best aroma of fresh-cut

365 tomatoes enriched with $3 \%$ DWP. Samples treated with $3 \%$ had significantly higher scores

366 for general acceptability and fresh appearance than samples treated with chlorine (control).

367 Other parameters evaluated by the sensory panel, such as, color had no significant

368 differences between treatments.

369 Nutritional markers

$370 \quad$ Ascorbic acid

371 The polynomial model explained $86.56 \%$ of the variability of ascorbic acid due to storage

372 time and concentration of DWP (Eq. 6). The model predicted data showed in contour plots,

373 Figure $3 \mathrm{~A}$, where a significant $(\mathrm{p}<0.05)$ linear effect of the storage time was observed. 
374 Ascorbic acid content is an indicator of quality in fresh-cut vegetables and considered one

375 of the best sources of vitamin $\mathrm{C}$ by consumers. The initial (storage time 0 ) value of ascorbic

376 acid was $19 \mathrm{mg} / 100 \mathrm{~g} \mathrm{FW}$. This is within the range of 6.96 to $21.23 \mathrm{mg} / 100 \mathrm{~g}$ FW for

377 tomatoes as reported by Toor and Savage (25). The recovery of the method was $94.2 \%$.

378 The LOD, LOQ and precision were $<0.20 \mathrm{mg} / 100 \mathrm{~g},<0.65 \mathrm{mg} / 100 \mathrm{~g}$ and $1.4 \%$

379 respectively. Ascorbic acid content significantly (linearly) reduced during storage time. The

380 highest ascorbic acid levels were found in $5 \%$ DWP treated samples with no significant

381 difference ( $>>0.05)$ using concentrations over $3 \%$.

$382 Y_{\text {Ascorbic Acid }}=19.36484+0.12600 X_{1}-0.45242 X_{2} ; R^{2}=86.56 \%$

\section{Lycopene}

384 Lycopene content was evaluated throughout storage time at different DWP concentrations.

385 The model for lycopene content with the two independent variables, storage and

386 concentration of DWP is described in Eq. 7. A significant $(\mathrm{p}<0.05)$ linear effect of the

387 storage time and quadratic effect of DWP concentration were observed (Figure 3B).

$Y_{\text {Lycopene }}=3.83442+0.86401 X_{1}+0.25972 X_{2}-0.13375 X_{1}^{2} ; R^{2}=90.70 \%$

390 Storage time was the most important factor affecting the samples. The lycopene content

391 increased significantly $(\mathrm{p}<0.05)$ during storage. The increase in the lycopene concentration

392 might be due to the biosynthesis of lycopene induced by ripening. DWP concentration also

393 affected the lycopene content of the samples. The highest lycopene levels were found in 3

$394 \%$ DWP treated samples.

395 Total phenols 
396 Model described in Eq. 8 explained $95.27 \%$ of the total phenols. A significant $(\mathrm{p}<0.05)$

397 linear effect of the storage time and quadratic effect of DWP concentrations on the total

398 phenol content was observed.

$399 Y_{\text {Total Phenol }}=20.23503+1.19723 X_{1}-0.32900 X_{2}-0.17667 X_{1}^{2} ; R^{2}=95.27 \%$

400 Total phenol content (Figure 3C) of the samples significantly $(\mathrm{p}<0.05)$ decreased over

401 storage. The initial value of total phenols in samples was $20.3 \mathrm{mg} \mathrm{GAE} / 100 \mathrm{~g} \mathrm{FW}$. This

402 result is in agreement with other studies (25). At the end of the storage the levels of total

403 phenols reached $17.8 \mathrm{mg}$ GAE/100 g FW. Phenolics are the major antioxidant compounds

404 in plant extracts. Toor and Savage (25) reported that phenolic compounds might contribute

40560 to $70 \%$ antioxidant activity of tomato extracts. The optimum DWP concentration was 3

$406 \%$ for total phenol retention of fresh-cut tomato.

407 Antioxidant activity test - ferric ion reducing antioxidant power assay (FRAP)

408 Ferric ion reducing antioxidant power (FRAP) is one of the most commonly used

409 antioxidant capacity assay (17). The polynomial model explained $96.88 \%\left(\mathrm{R}^{2}\right)$ of the

410 variability of antioxidant activity as measured by FRAP due to storage time and DWP

411 treatment concentration.

$412 Y_{F R A P}=82.11696+1.14875 X_{1}-4.43818 X_{2}+0.19422 X_{2}^{2} ; R^{2}=96.88 \%$

413 Figure 3D shows the variation of FRAP at different DWP concentrations and over storage

414 time. Storage had significant $(\mathrm{p}<0.05)$ linear and quadratic effects on the FRAP values of

415 fresh-cut tomatoes. Antioxidant activity as measured by FRAP decreased significantly

416 during storage. DWP concentrations showed only linear effect with significant increase

417 with increasing concentrations.

418 Microbiological markers

419 Total aerobic counts 
420 Figure 4A shows a significant linear increase of total aerobic counts over storage time. The

421 model described in Eq. 10 explained $96.91 \%$ of aerobic load variation.

$422 Y_{\text {Total Aerobic Counts }}=6.39038-1.83525 X_{1}+0.11953 X_{2}+0.22859 X_{1}^{2} ; R^{2}=96.91 \% \ldots$ (11)

423 The initial loads of total aerobic counts were approximately $6.25 \mathrm{log}$ CFU/g in fresh-cut

424 tomatoes stored at $4{ }^{\circ} \mathrm{C}$. DWP concentration also significantly $(\mathrm{p}<0.05)$ affected the aerobic

425 counts of fresh-cut tomato (linear and quadratic effects), resulting in a positive effect for the

426 extension of the shelf-life. DWP concentration (3\%) reduced (linear and quadratic effects)

427 aerobic counts by $\sim 1.5 \log \mathrm{cfu} / \mathrm{g}$ after 10 days of storage. DWP treatment of $3 \%$ had

428 similar microbial load values to chlorine over storage (data not shown).

429 The antimicrobial application of whey has received considerable attention. Whey

430 antimicrobial properties have been reported widely in the literature but mainly based on the

431 in vitro trials $(2,26)$. Although the mechanism of antimicrobial activity of whey permeate is

432 still unknown, several have been proposed. The most likely factor is the acid $\mathrm{pH}$ of the

433 wash treatment which can have a direct effect on the initial microbial count reduction and

434 on subsequent growth during storage. Another factor can be the presence of lactic acid,

435 which can enter the cells in an un-dissociated form. And finally, the presence of

436 antibacterial peptides in the whey permeate might contribute to its antimicrobial capacity

437 (27). Antimicrobial peptides have been identified from whey protein hydrolysates. The

438 most studied are the lactoferrins. Additionally, a few antimicrobial peptides have been

439 identified from $\alpha_{\mathrm{S} 1}$-casein and $\alpha_{\mathrm{S} 2}$-casein (28). These antimicrobial peptides act against

440 different gram-positive and gram-negative bacteria (Escherichia, Helicobacter, Listeria,

441 Salmonella and Staphylococcus), yeasts and filamentous fungi (2, 26). The amphipathic

442 nature of these peptides presumably underlies their biological activities which enables them

443 to associate with lipid membranes and disrupt normal membrane functions of bacteria. The 
444 mechanism of action has been investigated for whey antimicrobial peptides by Saint-

445 Sauveur et al. (29). The killing mechanism found for most peptides investigated consists of

446 attacks on the outer and inner membranes, ultimately resulting in lysis of the bacteria. The

447 disruption of normal membrane permeability is at least partly responsible for the

448 antibacterial mechanism of lactoferricins.

\section{$449 \quad$ Yeast and moulds}

450 The model described in Eq. 11 explained $96.62 \%$ of yeast and moulds load variation. A

451 significant $(\mathrm{p}<0.05)$ linear increase of yeast and moulds over storage was observed. A

452 significant $(\mathrm{p}<0.05)$ reduction (linear and quadratic effects) with increasing DWP treatment

453 concentration occurred (Figure 4B).

$454 Y_{\text {Yeast and Moulds }}=5.80510-1.23220 X_{1}+0.40297 X_{2}-0.099643 X_{1} \times X_{2}+0.18917 X_{1}^{2} ; R^{2}=$

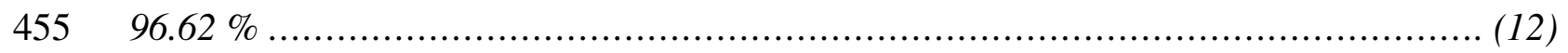

456 Fresh-cut tomatoes stored at $4{ }^{\circ} \mathrm{C}$ had initial loads of yeast and moulds approximately 5.59

$457 \log \mathrm{CFU} / \mathrm{g}$. This result was in agreement with the finding of Prakash et al. (30) for diced

458 tomato. Yeast and moulds load increased in all the samples over storage. DWP treatment

459 reduced $(3 \%)$ yeast and moulds counts by $\sim 1.0 \log \mathrm{cfu} / \mathrm{g}$ after 10 days of storage. The

460 values of DWP treated samples at the end of the storage were lower than the recommended

$461 \quad 10^{8} \mathrm{CFU} / \mathrm{g}$ for consumer consumption of fresh-cut vegetables (7).

\section{Validation of the model}

463 Despite some variations, results obtained from the validated predicted model and actual 464 experimental values showed that the established models reliably predicted the markers 465 studied. The predicted values were in close agreement with experimental values (Table 3) 466 and were found to be not significantly different at $\mathrm{p}>0.05$ using a paired t-test. In addition 467 variations between the predicted and experimental values obtained for all the markers 
468 studied were within acceptable error range as depicted by average mean deviation (E\%,

469 Table 3). Therefore, the predictive performance of the established model may be considered

470 acceptable.

471 Application of the response surface methodology indicated the suitability of $3 \%$ DWP as a

472 natural preservative ingredient to extend the shelf-life of fresh-cut tomato. Variations in

473 DWP concentration in the range evaluated (0 to $5 \%$ ) were critical in some of the markers

474 studied, such as, texture, sensory, aerobic counts and yeast and moulds. Higher DWP

475 concentrations maintained the quality better than lower concentrations, i.e. maintaining

476 texture, total aerobic counts and yeast and moulds. However, perceived off-odors due to

477 DWP addition over $3 \%$, and so the reduction of sensory scores in general acceptability,

478 suggested that the use of $3 \%$ of DWP in order to obtain a balance between quality and 479 nutritional values. Also the naturally present antioxidants, such as ascorbic acid and 480 lycopene were retained best within the range of 3 to $5 \%$ of DWP treatment. Further 481 research with pathogens to assess the efficacy of DWP as a natural preservative for fresh482 cut tomato is recommended.

\section{ACKNOWLEDGEMENT}

484 The authors would like to acknowledge the financial support of the DIT Strand I Research 485 Project (2006-2010). Thanks to Glanbia (Ltd Ingredients, Ireland) for supplying the whey 486 permeate, to Amcor Flexible Ltd. for providing OPP film and to Sharp Interpack for the 487 polypropylene trays. 488 
490 (1) Contreras, del M. M.; Hernández-Ledesma, B.; Amigo, L.; Martín-Álvarez, P. J.;

491 Recio, I. Production of antioxidant hydrolyzates from a whey protein concentrate with

492 thermolysin: Optimization by response surface methodology. LWT - Food Sci.

493 Technol. 2010, doi:10.1016/j.lwt.2010.06.017.

494 (2) Rizzello, C. G.; Losito, I.; Gobbetti, M.; Carbonara, T.; Bari, de M. D.; Zambonin, P.

495 G. Antibacterial activities of peptides from the water-soluble extracts of Italian cheese

496 varieties. J. Dairy Sci. 2005, 88, 2348-2360.

497 (3) Yalcin, A. S. Emerging Therapeutic Potential of Whey Proteins and Peptides. Curr.

498 Pharma. Des. 2006, 12 (13), 1637-1643.

499 (4) Panesar, P. S.; Kennedy, J. F.; Gandhi, D. N.; Bunko, K. Bio-utilisation of whey for $500 \quad$ lactic acid production. Food Chem. 2007, 105, 1-14.

501 (5) Martin-Diana, A. B.; Rico, D.; Frias, J. M.; Mulcahy, J.; Henehan, G. T. M.; Barry-

502 Ryan, C. Whey permeate as a bio-preservative for shelf life maintenance of fresh-cut 503 vegetables. Innov. Food Sci. Emerg. Technol. 2006, 7, 112-123.

504 (6) Ahmed, L.; Martin-Diana, A. B.; Rico, D.; Barry-Ryan, C. The antioxidant properties 505 of whey permeate treated fresh-cut tomatoes. Food Chem. 2010, doi: $506 \quad$ 10.1016/j.foodchem.2010.07.106.

507 (7) Alegria, C.; Pinheiro, J.; Gonçalves, E. M.; Fernandes, I.; Moldão, M. Evaluation of a 508 pre-cut heat treatment as an alternative to chlorine in minimally processed shredded 509 carrot. Innov. Food Sci. Emerg. Technol. 2010, 11, 155-161.

510 (8) Rojas-Graü, M. A.; Soliva-Fortuny, R.; Martín-Belloso, O. Edible coatings to 511 incorporate active ingredients to fresh-cut fruits: A review. Trends Food Sci. Technol. $512 \quad 2009,20(10), 438-447$. 
513 (9) Sgherri, C.; Kadlecova, Z.; Pardossi, A.; Navari-Izzo, F.; Izzo, R. Irrigation with

514 diluted sea water improves the nutritional value of cherry tomatoes. J. Agricult. Food $515 \quad$ Chem. 2008, 56, 3391-3397.

516 (10) Odriozola-Serrano, I.; Soliva-Fortuny, R.; Martin-Belloso, O. Effect of minimal 517 processing on bioactive compounds and color attributes of fresh-cut tomatoes. $L W T$ $518 \quad$ Food Sci. Technol. 2008, 41, 217-226.

519 (11) Rico, D.; Martín-Diana, A. B.; Barry-Ryan, C.; Frías, J. M.; Henehan, G. T. M.; 520 Barat, J. M. Optimisation of steamer jet-injection to extend the shelf-life of fresh-cut $521 \quad$ lettuce. Postharvest Biol. Technol. 2008, 48, 431-442.

522 (12) Ghodke, S. K.; Ananthanarayan, L.; Rodrigues, L. Use of response surface 523 methodology to investigate the effects of milling conditions on damaged starch, dough 524 stickiness and chapatti quality. Food Chem. 2009, 112(4), 1010-1015.

525 (13) Ferreira, V. O.; Pinho, O.; Amaral, M.; Martins, I. Application of blended-learning 526 strategies on sensory analysis teaching. In M. Munoz, I. Jelinek, \& F. Ferreira (Eds.). 527 Proceedings of the IASK International Conference Teaching and Learning. Aveiro, 528 Portugal. 2008, (pp. 262-270).

529 (14) Lee H.S.; Castle, W.S. Seasonal changes of carotenoid pigments and color in Hamlin, 530 Eartygold, and Budd Blood orange juices. J. Agricult. Food Chem. 2001, 49, 877531882.

532 (15) Shi, J.; Maguer, le M. Lycopene in tomatoes: chemical and physical properties 533 affected by food processing. Crit. Rev. Food Sci. Nutr. 2000, 40(1), 1 - 42.

534 (16) Singleton, V. L.; Orthofer, R.; Lamuela-Raventos, R. R. Analysis of total phenols and 535 other oxidation substrates and oxidants by means of Folin-Ciocalteu reagent. Methods $536 \quad$ Enzymol. 1999, 299, 152-178. 
537 (17) Stratil, P.; Klejdus, B.; Kuban, V. Determination of total content of phenolic

538 compounds and their antioxidant activity in vegetables - evaluation of

539 spectrophotometric methods. J. Agricult. Food Chem. 2006, 54, 607-616.

540 (18) Cortés, C.; Esteve, M. J.; Frigola, A. Colour of orange juice treated by high intensity

541 pulsed lectric fields during refrigerated storage and comparison with pasteurized juice.

$542 \quad$ Food Control. 2008, 19, 151-158.

543 (19) Roura, S.; Davidovch, L.; Valle, del C. Postharvest changes in fresh under different $544 \quad$ storage conditions. J. Food Qual. 2000, 23, 143-147.

545 (20) Diaza, O.; Pereirab, C. D.; Cobos, A. Functional properties of ovine whey protein 546 concentrates produced by membrane technology after clarification of cheese 547 manufacture by-products. Food Hydrocolloid. 2004, 18, 601-610.

548 (21) Chardonnet, C. O.; Charron, C. S.; Sams, C. E.; Conway, W.S. Chemical changes in 549 the cortical tissue and cell walls of calcium infiltrated 'Golden Delicious' apples 550 during storage. Postharvest Biol. Technol. 2003, 28, 97-111.

551 (22) Lana, M. M.; Tijskens, L. M. M.; Kooten, van O. Effects of storage temperature and 552 stage of ripening on RGB colour aspects of fresh-cut tomato pericarp using video 553 image analysis. J. Food Eng. 2006, 77, 871-879.

554 (23) Silveira, A. C.; Aguay, E.; Artés, F. Emerging sanitizers and Clean Room packaging 555 for improving the microbial quality of fresh-cut 'Galia' melon. Food Control. 2010, $556 \quad 21,863-871$.

557 (24) Aguayo, E.; Escalona, V. H.; Artes F. Effect of cyclic exposure to ozone gas on 558 physicochemical, sensorial and microbial quality of whole and sliced tomatoes. 559 Postharvest Biol. Technol. 2006, 39, 169-177. 
560 (25) Toor, R. K.; Savage, G. P. Antioxidant activities in different fractions of tomato. Food

$561 \quad$ Res. Intern. 2005, 38, 487-494.

562 (26) Fitzgerald, R. J.; Murray, B. A. Bioactive peptides and lactic fermentations. Int. J. 563 Dairy Technol. 2006, 59, 118-125.

564 (27) Clare, D. A.; Swaisgood, H. E. Bioactive milk peptides (6). J. Dairy Sci. 2000, 83, $565 \quad 1187-1195$.

566 (28) Mccann, K. B.; Shiell, B. J.; Michalski, W. P.; Lee, A.; Wan, J.; Roginski, H.;

567 Coventry, M. J. Isolation and characterization of a novel antibacterial peptide from 568 bovine $\alpha_{\mathrm{S} 1}$-casein. Int. Dairy J. 2006, 16, 316-323.

569 (29) Saint-Sauveur, D.; Gauthier, S. F.; Boutin, Y.; Montoni, A. Immunomodulating 570 properties of a whey protein isolate, its enzymatic digest and peptide fractions. Int. $571 \quad$ Dairy J. 2008, 18, 260-270.

572 (30) Prakash, A.; Guner, A.; Caporaso, F.; Foley, D. Effects of low-dose gamma 573 irradiation on the shelf-life and quality characteristics of cut Romaine lettuce 574 packaged under modified atmosphere. J. Food Sci. 2000, 65(3), 549-553. 


\section{$576 \quad$ Figure captions}

577 Figure 1. Contour plots showing the effect of DWP concentration $(0-5 \%)$ and storage

578 time (0 - 10 days) on $\mathrm{O}_{2}(\mathrm{~A}), \mathrm{CO}_{2}(\mathrm{~B}), \mathrm{pH}(\mathrm{C})$ and texture (D) in fresh-cut tomato packaged

579 and stored at $4{ }^{\circ} \mathrm{C}$.

580 Figure 2. Sensory evaluation of fresh-cut tomatoes packaged and stored for 10 days at $4{ }^{\circ} \mathrm{C}$

581 and washed with 3 different concentrations of DWP and $120 \mathrm{ppm}$ chlorine.

582 Figure 3. Contour plots showing the effect of DWP concentration $(0-5 \%)$ and storage

583 time (0 - 10 days) on Ascorbic acid (A), lycopene (B), TP (C) and antioxidant activity -

584 FRAP (D) in fresh-cut tomato packaged and stored at $4{ }^{\circ} \mathrm{C}$.

585 Figure 4. Contour plots showing the effect of DWP concentration $(0-5 \%)$ and storage

586 time (0 - 10 days) on total aerobic counts (A) and yeast and moulds (B) in fresh-cut tomato

587 packaged and stored at $4{ }^{\circ} \mathrm{C}$. 
Table 1. Response surface methodology design

\begin{tabular}{lll}
\hline Points & DWP Concentration (\%) & Storage (Days ) \\
\hline 1 & 0.550253 & 3 \\
2 & 5.5 & 3 \\
3 & 5.5 & 0.171573 \\
4 & 5.5 & 3 \\
5 & 10.4497 & 3 \\
6 & 9 & 1 \\
7 & 2 & 1 \\
8 & 9 & 5 \\
9 & 5.5 & 3 \\
10 & 2 & 5 \\
11 & 5.5 & 5.82843 \\
\hline
\end{tabular}


Table 2. Analysis of variance of the regression coefficients of the fitted quadratic equation for color.

\begin{tabular}{llllll}
\hline Coefficient & $\mathrm{L}^{*}$ & $\mathrm{a}^{*}$ & $\mathrm{~b}^{*}$ & Hue & Chroma \\
\hline$\beta_{0}$ (intercept) & 44.5288 & 13.48 & 21.8602 & 57.0723 & 25.0536 \\
Linear & & & & \\
$\beta_{1}$ (Concentration) & $0.280479^{\mathrm{ns}}$ & $0.0410426^{\mathrm{s}}$ & $0.302278^{\mathrm{ns}}$ & $0.483391^{\mathrm{ns}}$ & $0.0628907^{\mathrm{ns}}$ \\
$\beta_{2}$ (Storage) & $-0.28366^{\mathrm{s}}$ & $-0.0030048^{\mathrm{s}}$ & $-0.580779^{\mathrm{s}}$ & $-0.250071^{\mathrm{s}}$ & $-0.17084^{\mathrm{s}}$ \\
Quadratic & & & & & \\
$\beta_{11}$ (Concentration) & $-0.0539062^{\mathrm{ns}}$ & $0.00307281^{\mathrm{ns}}$ & $-0.0234375^{\mathrm{ns}}$ & $-0.0614579^{\mathrm{ns}}$ & $0.00119798^{\mathrm{ns}}$ \\
$\beta_{22}$ (Storage) & $0.00566294^{\mathrm{ns}}$ & $0.00651372^{\mathrm{ns}}$ & $-0.0234375^{\mathrm{ns}}$ & $-0.0357834^{\mathrm{ns}}$ & $0.00464286^{\mathrm{ns}}$ \\
Cross product & & & & & \\
$\beta_{12}$ & $0.0075^{\mathrm{ns}}$ & $0.00214286^{\mathrm{ns}}$ & $0.00821429^{\mathrm{ns}}$ & $-0.00392857^{\mathrm{ns}}$ & $0.00464286^{\mathrm{ns}}$ \\
$\mathrm{R}^{2}$ & 79.21 & 87.60 & 90.66 & 95.21 & 85.32 \\
$P$-value & 0.0061 & 0.0008 & 0.0001 & $<0.0001$ & 0.0005 \\
\hline $\begin{array}{l}\mathrm{s}=\text { significant at } \mathrm{p}<0.05 \\
\mathrm{~ns}=\text { non-significant }\end{array}$ & & & &
\end{tabular}


Table 3. Experimental and predicted values and average mean deviation (E \%) for all the markers studied of fresh-cut tomatoes treated with $3 \%$ DWP at day 10.

\begin{tabular}{llll}
\hline Markers & Experimental Value & Predicted Value & E\% \\
\hline $\mathrm{O}_{2}(\%)$ & 13.2 & 13.53 & 0.83 \\
$\mathrm{CO}_{2}(\%)$ & 7.2 & 7.01 & 0.88 \\
$\mathrm{pH}$ & 4.82 & 4.98 & 1.11 \\
Firmness (N) & 2.9 & 2.93 & 0.34 \\
$\mathrm{~L}^{*}$ & 43.19 & 42.62 & 0.44 \\
$\mathrm{a}^{*}$ & 14.36 & 14.25 & 0.26 \\
$\mathrm{~b}^{*}$ & 17.93 & 18.39 & 0.86 \\
$\mathrm{Hue}$ & 52.5 & 52.01 & 0.31 \\
Chroma & 23.08 & 23.34 & 0.38 \\
Ascorbic acid (mg/ 100 g FW) & 16.22 & 16.87 & 1.34 \\
Lycopene (mg/ 100 g FW) & 6.86 & 6.99 & 0.63 \\
TP (mg Gallic acid/ 100 g FW) & 18.2 & 18.09 & 0.20 \\
FRAP (mg Trolox/ 100 g FW) & 63.11 & 63.25 & 0.07 \\
Total aerobic counts (log cfu/g) & 7.18 & 6.88 & 1.39 \\
Yeast and moulds (log cfu/g) & 7.38 & 7.34 & 0.18 \\
\hline
\end{tabular}


Figure 1

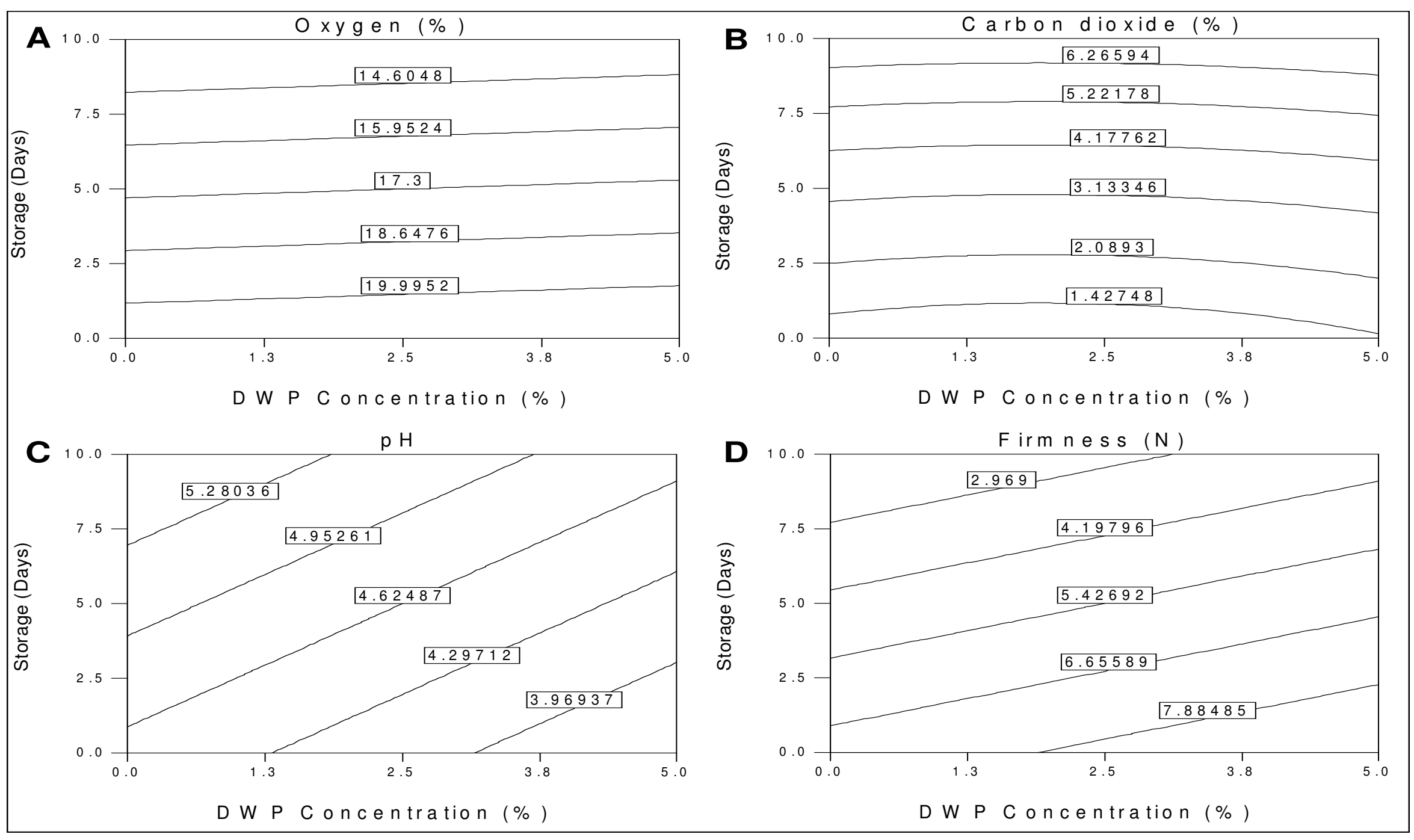


Figure 2

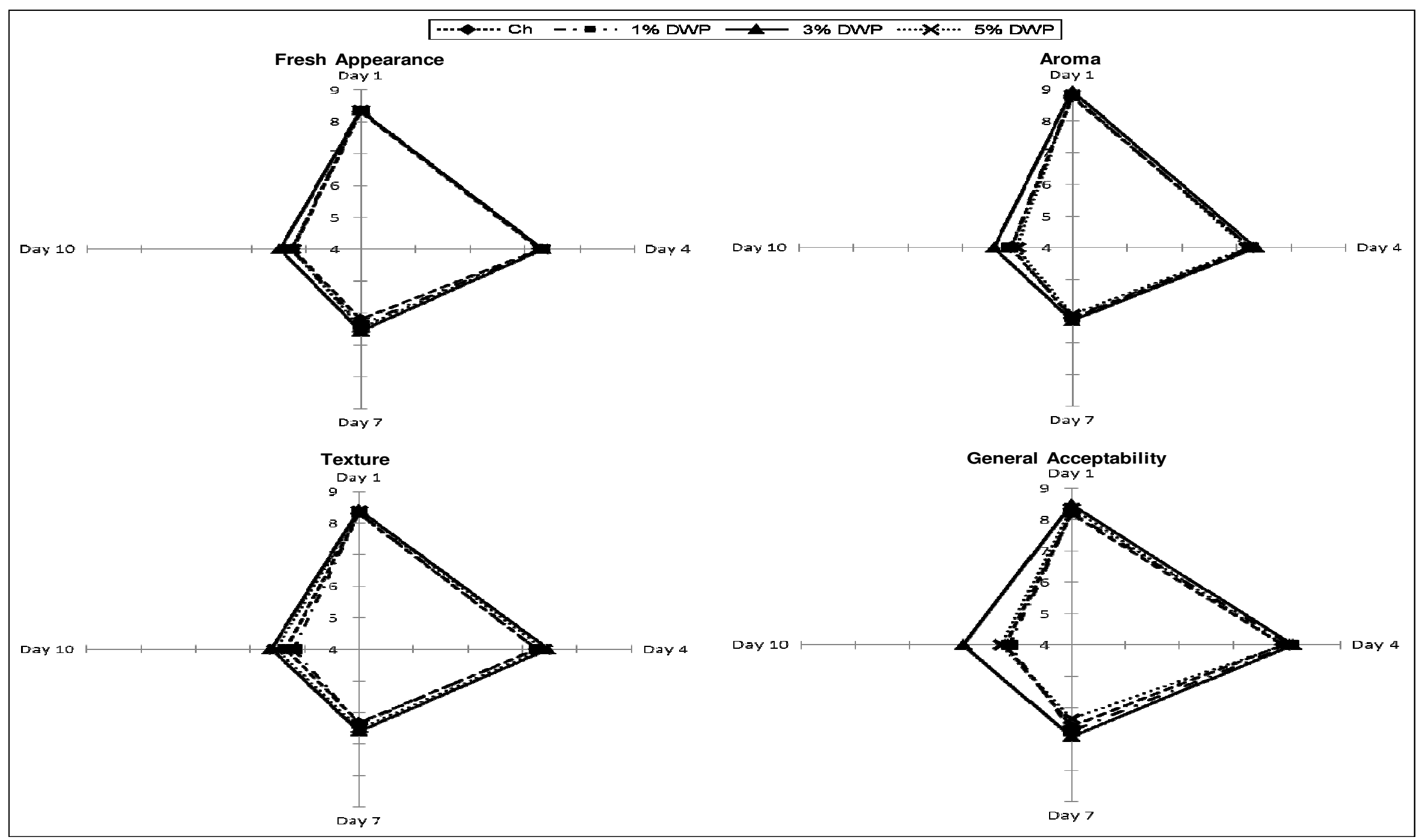

31 


\section{Figure 3}

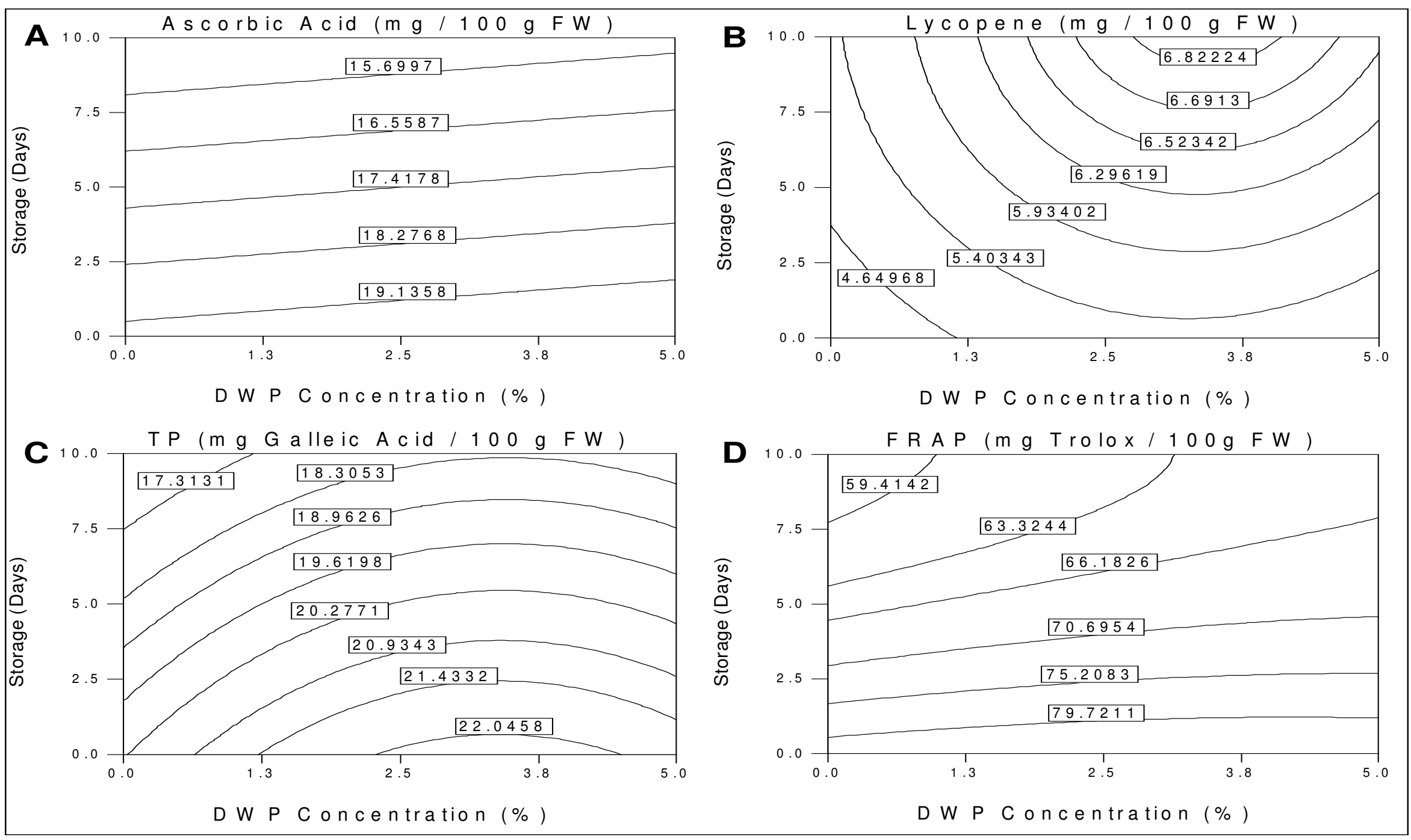




\section{Figure 4}

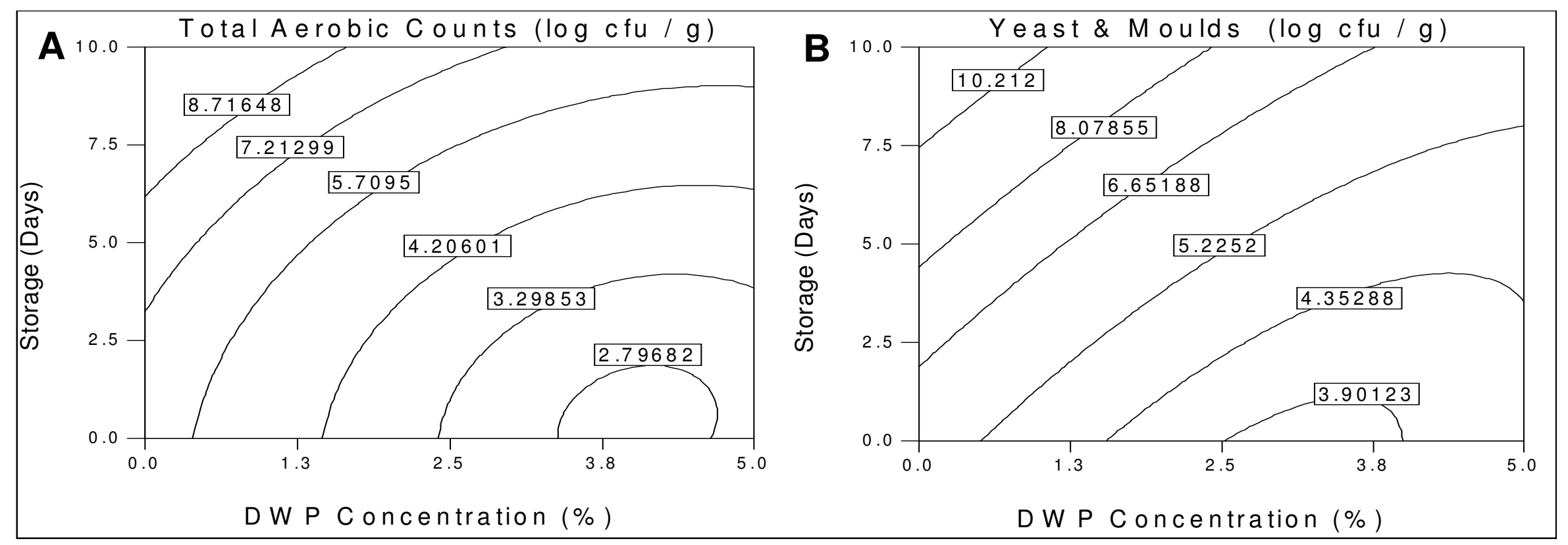

